\title{
In Memoriam Léon Wurmser
}

\section{Cord Benecke • Anna Ursula Dreher · Michael Ermann · Jürgen Körner • Ulrich Lamparter • Diana Pflichthofer • Timo Storck}

Léon Wurmser ist am 14. Februar in hohem Alter von 89 Jahren gestorben. Die vielen Menschen, denen er auf Tagungen, bei Vorträgen und in seinen unvergessenen kasuistischen Seminaren begegnet ist, die ihn kannten und schätzten, ist sein Tod ein trauriger Verlust. Mit seiner warmherzigen, respektvollen Art und seinem aufrichtigen Interesse war er für viele ein Vorbild, an dem man sich orientieren konnte. Seine Arbeiten über das Überich und die Scham sind Marksteine der psychoanalytischen Theoriegeschichte.

Wurmser trat bald nach der Gründung in den internationalen Beirat unserer Zeitschrift ein und bereicherte sie durch mehrere originelle Beiträge, darunter seine grundlegende Arbeit über das Schamsyndrom, die 1986 erschien und viel Beachtung gefunden hat. Dafür sind wir ihm dankbar.

Zu seinem Gedenken drucken wir hier seinen Beitrag aus dem Forum 2005, der wie wenige andere seine Philosophie und seine zutiefst menschlichen Haltung als Psychoanalytiker ,,auf den Punkt“" bringt:

Einige Gedanken zum Thema psychoanalytische Identität und Zeit*

* Zuerst erschienen in Forum Psychoanal $2005 \cdot 21: 130-142$

Prof. Dr. M. Ermann ( $\square)$

Innsbrucker Str. 56, 10825 Berlin, Deutschland

E-Mail: Michael.Ermann@t-online.de 